\title{
Knowledge about diagnostic features and comorbidities of childhood autism among doctors in a tertiary care hospital
}

\author{
*Yasodha Maheshi Rohanachandraㄹ, Dulangi Maneksha Amerasinghe Dahanayake², Lochana Thivanka \\ Rohanachandra $^{3}$, Gampolage Swarna Wijetunge ${ }^{2}$
}

Sri Lanka Journal of Child Health, 2017; 46(1): 29-32

\begin{abstract}
Introduction: Epidemiological surveys indicate that the prevalence of autism is rising worldwide. A study in Sri Lanka has shown 1 in 93 children to be affected. Early diagnosis is vital as early intensive behavioural interventions improve outcome in autism. It has been shown that the level of physicians' knowledge of autism influences the average age of diagnosis and provision of further information to caregivers.
\end{abstract}

Objectives: To assess the knowledge of diagnostic features and comorbidities of childhood autism among doctors in a tertiary care hospital and to identify the factors affecting it.

Method: A descriptive study was conducted on 176 doctors at Colombo South Teaching Hospital, using the Knowledge about Childhood Autism among Health Workers Questionnaire. Data was collected by authors and analyzed using SPSS version 21. Ethical approval was obtained from the ethical review committee of the Lady Ridgeway Hospital.

Results: Majority (61.9\%) considered themselves incompetent in identifying autism. Knowledge was highest regarding symptoms of impaired social interactions $(75.81 \%)$ and lowest for restricted repetitive interests/behaviours $(60.79 \%)$, with a significant difference between medical officers and postgraduate trainees $(\mathrm{p}=0.045)$.

${ }^{1}$ Department of Psychiatry, University of Sri Jayewardenepura, Sri Lanka, ${ }^{2}$ Lady Ridgeway Hospital for Children, Sri Lanka, ${ }^{3}$ Colombo South Teaching Hospital, Sri Lanka

*Correspondence: yasodha_mk@yahoo.com

(Received on 06 March 2016: Accepted after revision on 22 April 2016)

The authors declare that there are no conflicts of interest

Personal funding was used in formulating the article.

Open Access Article published under the Creative Commons Attribution CC-BY (C) (P) License.
Conclusions: Knowledge regarding childhood autism is poor among doctors in the tertiary hospital studied.

DOI: http://dx.doi.org/10.4038/sljch.v46i1.8093

(Key words: Knowledge, autism, doctors)

\section{Introduction}

Epidemiological surveys worldwide demonstrate a rising prevalence of autism and a Sri Lankan study has shown 1 in 93 children to be affected ${ }^{1}$. Early diagnosis is vital as early intensive behavioural interventions improve adaptive behaviour, language and intelligence in autism ${ }^{2}$ and diagnostic delays can worsen prognosis ${ }^{3}$. Therefore, to improve quality of life of affected children and care givers, it is crucial that health care providers are aware of the features of autism to enable early diagnosis and intervention.

Studies done in several countries have revealed inadequacies in knowledge about autism among doctors, with a variation between primary care providers and specialists ${ }^{4-6}$. The average delay from first presentation to diagnosis is estimated to be 4 years ${ }^{2}$. It has been demonstrated that the level of physicians' knowledge of autism greatly influences the average age of diagnosis and provision of further information to caregivers ${ }^{3}$.

In Sri Lanka, medical professionals involved in primary health care have a pivotal role in identification and referral of children with autism, since child psychiatric services are, as yet, underdeveloped and unable to cater for the majority. As the knowledge of medical professionals in identification of children with autism has not been assessed previously, it would be important to do so in order to plan in-service training programmes, which will facilitate early diagnosis and intervention in children with autism.

\section{Objectives}

To assess the knowledge of diagnostic features and comorbidities of childhood autism among doctors in a tertiary care hospital and to identify the factors affecting it. 


\section{Method}

A descriptive study was done among doctors at Colombo South Teaching Hospital, from July to September 2015. All consenting intern medical officers, medical officers and registrars were included in the study. Doctors from psychiatry units were excluded as they have received special training and have experience in diagnosing autism. Similarly, consultants were excluded as their knowledge may not reflect the knowledge of non-specialist doctors. A specifically designed questionnaire for sociodemographic details and the "Knowledge about Childhood Autism among Health Workers (KCAHW) Questionnaire" were used. KCAHW questionnaire was developed in Nigeria, and is recommended for use in developing countries ${ }^{7}$.The questionnaire utilizes widely accepted symptoms of autism that are taught in medical schools in Sri Lanka in English. This has a total of nineteen questions divided into four domains; namely impairments in social interactions, impairment of communication and language development, restricted, repetitive and stereotyped behaviour and common associations of childhood autism. Each of the questions has three options (yes, no, don't know) to choose from with only one of these options being correct. The correct option for each question is given a score of one, while the other two options that are incorrect are given a score of zero each. A maximum and minimum total score of nineteen and zero respectively are possible. The test-retest reliability of the questionnaire is good as there were significant correlations in the mean domain and mean total scores at first and second time of administration. The KCAHW questionnaire also has a good internal consistency as revealed in the Cronbach's alpha value obtained for mean domain scores correlation with the mean total scores both at first and second time of administration. Data was analyzed using SPSS version 21. The mean KCAHW score was calculated. Independent sample t-test and ANOVA were used to test the difference in knowledge among groups. Informed consent was sought from participants. Ethical approval was obtained from the ethical review committee of the Lady Ridgeway Hospital.

\section{Results}

A total of 176 medical officers from the Colombo South Teaching Hospital participated in the study from July to September 2015. The demographic details of the 176 participants are shown in Table 1 . The mean age of the study group was $38.4 \pm 8.18$ years. Seventy eight $(45 \%)$ were working in a medical specialty.
Table 1: Demographic details of participants $n=176$

\begin{tabular}{|l|c|}
\hline \multicolumn{1}{|c|}{ Demographic detail } & No. (\%) \\
\hline Age & $32(18.2)$ \\
$<30$ years & $73(41.5)$ \\
$30-40$ years & $51(29.0)$ \\
$41-50$ years & $16(09.1)$ \\
> 50 years & $04(02.2)$ \\
Missing & \\
\hline Sex & $65(36.9)$ \\
Male & $111(63.1)$ \\
Female & \\
\hline Designation & $22(12.5)$ \\
Intern Medical Officers & $131(74.4)$ \\
Medical Officers/Senior House Officers & $23(13.1)$ \\
Registrars & \\
\hline Current specialty & $78(44.3)$ \\
Medical & $34(19.3)$ \\
Surgical & $15(08.5)$ \\
Paediatrics & $10(05.7)$ \\
Gynaecology and obstetrics & $21(11.9)$ \\
OPD & $16(09.1)$ \\
Anaesthesia & $02(01.1)$ \\
Missing & \\
\hline Work experience & $23(13.1)$ \\
<1 year & $08(04.5)$ \\
1-5 years & $56(31.8)$ \\
5-10 years & $86(48.9)$ \\
>10 years & $03(01.7)$ \\
Missing & $64(36.4)$ \\
\hline Perceived competence & $109(61.9)$ \\
Competent & $03(01.7)$ \\
Not competent & \\
Missing & \\
\hline & \\
\hline
\end{tabular}

The participants scored a mean of 13.23/19 (69.1\%) in the questionnaire. The knowledge was highest in identification of symptoms related to impaired social interactions $(75.8 \%)$ and lowest in identification of symptoms of restricted repetitive interests and behaviours $(60.8 \%)$ (Table 2). For instance, 116 $(65.9 \%)$ knew that delay or lack of speech development was a feature of autism and 56.8\% knew that social smiling was absent in children with autism, but $49.4 \%$ were unaware that children with autism have a strong preference for regimented routine activities. Ninety three $(52.9 \%)$ of the participants were unaware that autism is associated with epilepsy and $72(40.9 \%)$ did not know that autism is associated with mental retardation.

The mean knowledge did not differ significantly with sex $(p=0.377)$, age $(p=0.169)$, years of experience $(p=0.326)$ or the specialty of work $(p=0.614)$. The postgraduate trainees had significantly better knowledge than the medical officers $(p=0.045)$ in identification of symptoms of autism. In addition, those who considered themselves competent in identifying autism had significantly better knowledge than those who did not $(\mathrm{p}=0.001)$. 
Table 2: Mean scores of the KCAHW questionnaire

\begin{tabular}{|l|c|c|c|}
\hline \multicolumn{1}{|c|}{ Domain } & $\begin{array}{c}\text { Yes } \\
\text { No. (\%) }\end{array}$ & $\begin{array}{c}\text { No } \\
\text { No. (\%) }\end{array}$ & $\begin{array}{c}\text { Don't know } \\
\text { No. (\%) }\end{array}$ \\
\hline $\begin{array}{l}\text { Domain 1 - Reciprocal social interactions } \\
\text { Marked impairment in use of multiple non-verbal behaviours during } \\
\text { social interaction }\end{array}$ & & & \\
Failure to develop peer relationship appropriate for developmental age & $159(90.3)$ & $09(05.1)$ & $08(04.5)$ \\
Lack of spontaneous will to share enjoyment, interest or activities with & & $05(02.8)$ & $10(05.7)$ \\
others & $146(83.0)$ & $17(09.7)$ & $13(07.4)$ \\
Lack of social or emotional reciprocity & $141(80.1)$ & $07(04.0)$ & $28(15.9)$ \\
Staring into open space and not focusing on anything specific & $92(52.3)$ & $55(31.3)$ & $29(16.5)$ \\
The child can appear as if deaf or dumb & $128(72.7)$ & $24(13.6)$ & $24(13.6)$ \\
Loss of interest in the environment and surroundings & $134(76.1)$ & $28(15.9)$ & $14(08.0)$ \\
Social smile is usually absent in a child with autism & $100(56.8)$ & $42(23.9)$ & $34(19.3)$ \\
\hline Domain 2 - Impairment in communication & & & \\
Delay or total lack of development of spoken language & $116(65.9)$ & $39(22.2)$ & $21(11.9)$ \\
\hline Domain 3 - Restricted repetitive interests and behaviours & & & \\
Stereotyped and repetitive movement (e.g. Hand or finger flapping) & $118(67.0)$ & $27(15.3)$ & $31(17.6)$ \\
May be associated with abnormal eating habit & $91(51.7)$ & $28(15.9)$ & $57(32.4)$ \\
Persistent preoccupation with parts of objects & $131(74.4)$ & $12(06.8)$ & $33(18.8)$ \\
Love for regimented routine activities & $89(50.6)$ & $37(21.0)$ & $50(28.4)$ \\
\hline Domain 4 - Common associations & & & \\
Autism is childhood schizophrenia & $06(03.4)$ & $142(80.7)$ & $28(15.9)$ \\
Autism is an auto-immune condition & $04(02.3)$ & $144(81.8)$ & $28(15.9)$ \\
Autism is a neuro-developmental disorder & $113(64.2)$ & $36(20.5)$ & $27(15.3)$ \\
Autism could be associated with mental retardation & $104(59.1)$ & $41(23.3)$ & $31(17.6)$ \\
Autism could be associated with epilepsy & $83(47.2)$ & $39(22.2)$ & $54(30.7)$ \\
\hline
\end{tabular}

\section{Discussion}

Although previous studies in Sri Lanka have demonstrated speech delay to be the commonest presentation to services ${ }^{9,10}, 34 \%$ of the doctors were unaware of this symptom. In addition, despite restrictive repetitive interests and behaviours being a diagnostic criterion of autism, $39 \%$ of the doctors did not recognize it as a part of autism. Inadequate knowledge on these domains may lead to delayed identification and intervention. Previous studies demonstrate that the knowledge on co-morbidities of autism is especially poor ${ }^{7,11}$. This also holds true for our study, with $53 \%$ being unaware of the association of epilepsy with autism. Poor knowledge results in attribution of these co-morbidities to be 'a part of autism', which leaves them untreated and worsen the quality of life of patients ${ }^{11}$.

Our study revealed that there was a significant difference in knowledge between medical officers and postgraduate trainees. This can be attributed to the additional training received by postgraduate trainees after completion of the MBBS. This stresses the importance of regular in-service programmes for medical officers to update their knowledge. However, other factors such as having a family member with autism and work experience in psychiatry could influence the difference in knowledge. Only 37\% of doctors rated themselves as competent in identifying autism. This may be the result of inadequate exposure to children with autism during their undergraduate period as specialized autism treatment programmes are not available in all teaching hospitals. Many medical faculties are now allocating their undergraduates to centres where such facilities are available, which may help improve the knowledge and competence of future doctors.

The implications of lack of knowledge about autism among health care providers include misdiagnosis, delayed diagnosis and delayed intervention. As early intensive behavioural interventions have been shown to improve adaptive behaviour, language and intelligence in autism, delay in diagnosis ultimately leads to poorer outcome ${ }^{3}$. In addition, it has been shown that due to inadequate knowledge, health care workers fail to offer information to carers, who in turn resort to other resources such as media and other parents. This may lead to carers receiving suboptimal information, leading to increased financial burden, family disharmony, increased caregiver challenges and increased risk of mental health problems among the parents ${ }^{3,8}$. 
The main limitation of this study is that it was carried out at a tertiary care centre. Knowledge of doctors in a tertiary care centre may not reflect that in other institutions. Ideally, this study is best carried out on doctors in primary health care, who are the first contact for child development. However, assessing the knowledge of doctors in a hospital setting is also important as it is the place where children identified by parents as having an abnormality present to, and failure of identification and referral at this stage would greatly impair prognosis.

\section{Conclusions and recommendations}

Knowledge of diagnostic features and comorbidities of childhood autism among doctors of the tertiary care hospital studied is poor. Further studies are needed to ascertain whether level of knowledge is similar among doctors in primary health care settings.

\section{Acknowledgements}

We thank Dr. Bakare for granting permission to use the KCAHW questionnaire.

\section{References}

1. Perera $\mathrm{H}$, Wijewardena $\mathrm{K}$, Aluthwelage $\mathrm{R}$. Screening of 18-24-month-old children for autism in a semi-urban community in Sri Lanka. Journal of Tropical Pediatrics 2009; 55(6):4025. http://dx.doi.org/10.1093/tropej/fmp031 PMid: 19401407

2. Dawson G. Early intensive behavioural intervention (EIBI) for young children with autism spectrum disorders (ASD). Journal of Pediatrics 2013; 162(5):1080-1. http://dx.doi.org/10.1016/j.jpeds.2013.02.049 PMid: 23617979

3. Rhoades RA, Scarpa A, Salley B. The importance of physician knowledge of autism spectrum disorder: results of a parent survey. BMC Pediatrics 2007; 7:37.

http://dx.doi.org/10.1186/1471-2431-7-37

PMid: 18021459 PMCid: PMC2235850

4. Bakare MO, Munir KM. Autism spectrum disorders (ASD) in Africa: a perspective. African Journal of Psychiatry 2011; 14(3):208-10. http://dx.doi.org/10.4314/ajpsy.v14i3.3

5. Imran N, Chaudry MR, Azeem MW, Bhatti MR, Choudhary ZI, Cheema MA. A survey of autism knowledge and attitudes among the healthcare professionals in Lahore, Pakistan. $B M C$ Pediatrics 2011; 11:107. http://dx.doi.org/10.1186/1471-2431-11-107

PMid: 22107951 PMCid: PMC3250946

6. Heidgerken DA, Geffken G, Modi A, Frakey L. A survey of autism knowledge in a health care setting. J Autism Dev Disord. 2005; 35(3):32330.

http://dx.doi.org/10.1007/s10803-005-3298-x

PMid: 16119473

7. Bakare MO, Ebigbo PO, Agomoh AO, Menkiti NC. Knowledge about childhood autism among health workers (KCAHW) questionnaire: description, reliability and internal consistency. Clin Pract Epidemiol Ment Health. 2008; 4:17. http://dx.doi.org/10.1186/1745-0179-4-17 PMid: 18538020 PMCid: PMC2430959

8. Eseigbe EE, Nuhu FT, Sheikh TL, Eseigbe P, Sanni KA, Olisah VO. Knowledge of childhood autism and challenges of management among medical doctors in Kaduna State, Northwest Nigeria. Autism Res Treat 2015.

9. Dahanayake DMA, Rohanachandra YM, Wijetunge GS. Factors affecting age at presentation of autism spectrum disorders: a descriptive survey from a child mental health clinic at Lady Ridgeway Hospital. Sri Lanka Journal of Psychiatry 2015; 6(1): 9-13. http://dx.doi.org/10.4038/sljpsyc.v6i1.8054

10. Perera $\mathrm{H}$, Jeewandara $\mathrm{KC}$, Guruge $\mathrm{C}$, Seneviratne S. Presenting symptoms of autism in Sri Lanka: analysis of a clinical cohort Sri Lanka. Sri Lanka Journal of Child Health 2013; 42(3): 139-43.

http://dx.doi.org/10.4038/sljch.v42i3.6017

11. National Autism Association [internet]. England: Treating Autism Publications; 2013. Medical Comorbidities in Autism Spectrum Disorders: A Primer for Health Care Professionals and Policy Makers. [cited 2015 December 12]. Available from:

http://nationalautismassociation.org/pdf/Medical ComorbiditiesinASD2013.pdf 